\title{
The loud first heart sound in left atrial myxoma
}

\author{
A H GERSHLICK, G LEECH, P G MILLS, A LEATHAM \\ From the London Hospital, and St George's Hospital, London
}

SUMmARY The interrelation between the loudness of the first heart sound, the time interval from the $Q$ wave to the onset of the first heart sound $\left(Q M_{1}\right)$, and the mitral valve closure rate was studied in nine patients presenting with left atrial myxomata. In seven patients the first heart sound was loud preoperatively and was associated with delayed mitral valve closure. After removal of the myxoma the onset of mitral valve closure returned towards normal, the mitral valve closure rate was reduced, and the first heart sound became softer. In two patients the first heart sound was normal before and after operation as were both the time of onset of mitral valve closure and the mitral valve closure rate. In neither of these patients did the myxoma completely fill the mitral orifice during diastole.

The loud first heart sound in left atrial myxoma is a useful clinical sign, and its intensity is directly related to the delay in onset of closure of mitral leaflets.

Although left atrial myxomas are rare, establishing a diagnosis is important since the risk of embolisation is high and surgical removal is usually successful with a low morbidity and mortality. Their presence may be suggested by symptoms produced by systemic emboli ${ }^{1}$ or by signs mimicking mitral stenosis. ${ }^{2-5} \mathrm{We}$ were impressed by the presence of a loud first heart sound associated with left atrial myxoma ${ }^{6}$ and investigated the mechanism and significance of this physical sign in the last nine patients presenting to our two hospitals.

\section{Patients and methods}

Table 1 shows the relevant clinical features of the nine patients.

High frequency phonocardiograms were recorded at the mitral area, and the ratio of the mitral component of the first sound $\left(M_{1}\right)$ to the aortic component of the second sound $\left(A_{2}\right)$ was calculated. This ratio gives a relative indication of the intensity of $M_{1}{ }^{7}$ and is particularly useful for comparisons of the intensity of the first heart sound within the same patient.

The interval from the onset of the QRS complex to the onset of the first high frequency vibrations of $M_{1}$ was measured $\left(Q M_{1}\right)$. In addition, the $P R$ interval was measured in patients in sinus rhythm.

Requests for reprints to Dr A H Gershlick, Cardiac Department, The London Hospital, London E1 1BB.

Accepted for publication 24 May 1984
The rate of closure of the anterior leaflet of the mitral valve was measured from the echocardiogram. This measurement was made on the B-C slope of mitral valve motion when the cusps are closing under the influence of ventricular systole.

All the above measurements were made over a minimum of three cardiac cycles and the mean value determined.

A paired $t$ test was used to compare the preoperative and postoperative results.

\section{Results}

In seven of the nine patients both the preoperative and postoperative echocardiograms and phonocardiograms were available for study. In two patients (cases 6 and 7) only preoperative data were available.

The patients were considered in two groups: those with a loud first heart sound (cases 1-7) and those whose first heart sound was soft (cases 8 and 9).

All the results are shown in Table 2.

\section{CASES $1-7$}

Intensity of $M_{1}$-The amplitude of $\mathrm{A}_{2}$ was used as a means of comparing the preoperative and postoperative intensity of $M_{1}$ in the five patients in whom this information was available. In these patients the mean value of $M_{1}: A_{2}$ fell from 2.02 preoperatively to 0.98 after removal of the myxoma (Table 2). Using a paired $t$ test the preoperative intensity of $M_{1}$ was statistically significantly greater than the postoperative recordings $(p<0.01, n=5)$. In the remaining 
Table 1 Clinical features of nine patients with left atrial myxoma

\begin{tabular}{|c|c|c|c|c|}
\hline $\begin{array}{l}\text { Case } \\
\text { No }\end{array}$ & $\begin{array}{l}\text { Age (yr) } \\
\text { and sex }\end{array}$ & Presenting symptoms & Physical signs & Operative findings \\
\hline 1 & $51 M$ & $\begin{array}{l}\text { Breathlessness, pyrexia, } \\
\text { palpitations }\end{array}$ & $\begin{array}{l}\text { Raised venous pressure, loud } S_{1} \text {, } \\
\text { soft pansystolic murmur }\end{array}$ & Gelatinous myxoma $(7 \times 5 \mathrm{~cm})$ \\
\hline 2 & $54 M$ & $\begin{array}{l}\text { Cough breathlessness, } \\
\text { palpitations }\end{array}$ & $\begin{array}{l}\text { Atrial fibrillation, loud } S_{1} \text {, } \\
\text { soft } S_{3}\end{array}$ & $\begin{array}{l}\text { "Large" myxoma attached to } \\
\text { atrial septum }\end{array}$ \\
\hline 3 & $17 M$ & Collapse, transient right hemiparesis & Loud $S_{1}^{3}$, late systolic murmur & Myxoma $(4 \times 4 \times 5 \mathrm{~cm})$ \\
\hline 4 & $40 \mathrm{~F}$ & $\begin{array}{l}\text { Episodes of loss of vision and } \\
\text { loss of peripheral pulses }\end{array}$ & Loud $S_{1}$ & $\begin{array}{l}\text { Myxoma attached to area of } \\
\text { foramen ovale }\end{array}$ \\
\hline 5 & 40F & $\begin{array}{l}\text { Breathlessness, palpitations, } \\
\text { flu-like illness, joint pains }\end{array}$ & $\begin{array}{l}\text { Loud } S_{1} \text {, late systolic murmur, } \\
\text { varying diastolic murmur }\end{array}$ & $\begin{array}{l}\text { Myxoma attached to area of } \\
\text { foramen ovale }\end{array}$ \\
\hline 6 & $57 M$ & Malaise, headache, nausea & $\begin{array}{l}\text { Loud } S_{1} \text {, pansystolic murmur, } \\
\text { embolus to aortic bifurcation } \\
\text { of entire myxoma }\end{array}$ & $\begin{array}{l}\text { Died one day before planned } \\
\text { cardiac surgery }\end{array}$ \\
\hline 7 & $35 \mathrm{~F}$ & $\begin{array}{l}\text { Breathlessness, pyrexia, joint } \\
\text { pains, palpitations }\end{array}$ & $\begin{array}{l}\text { Loud } S_{1} \text {, apical systolic } \\
\text { murmur, diastolic "plop" }\end{array}$ & $\begin{array}{l}\text { Myxoma attached just above } \\
\text { foramen ovale }\end{array}$ \\
\hline 8 & $17 F$ & $\begin{array}{l}\text { Right hemiparesis, aphasia, } \\
\text { discoloured painful fingers }\end{array}$ & Normal $S_{1}$, no murmurs & $\begin{array}{l}\text { Myxoma firmly attached just } \\
\text { above the mitral valve }\end{array}$ \\
\hline 9 & $19 \mathrm{~F}$ & Headache, malaise, meningitis & Normal $S_{1}$, no murmurs & Large sessile myxoma \\
\hline
\end{tabular}

Table 2 Measurements of $M_{1}: A_{2}, Q M_{1}$ time interval, terminal mitral valve closure rate, and $P R$ interval before and after operation

\begin{tabular}{|c|c|c|c|c|c|c|c|c|}
\hline \multirow[t]{2}{*}{ Case No } & \multicolumn{2}{|c|}{ Ratio of $M_{1}: A_{2}$} & \multicolumn{2}{|c|}{$Q M_{1}$ interval (ms) } & \multicolumn{2}{|c|}{ Mitral valve closure rate $(\mathrm{mm} / \mathrm{s})$} & \multicolumn{2}{|c|}{$P R$ interval (ms) } \\
\hline & Before & After & Before & After & Before & After & Before & After \\
\hline $\begin{array}{l}1 \\
2 \\
3 \\
4 \\
5 \\
6 \\
7 \\
8 \\
9\end{array}$ & $\begin{array}{l}2.63 \\
2.20 \\
2.36 \\
1.91 \\
1.02 \\
2.65 \\
4.75 \\
1.42 \\
1.50\end{array}$ & $\begin{array}{l}1.09 \\
1.16 \\
0.70 \\
1.16 \\
0.77 \\
= \\
\overline{1.65} \\
1.75\end{array}$ & $\begin{array}{r}90 \\
120 \\
110 \\
90 \\
90 \\
90 \\
100 \\
60 \\
50\end{array}$ & $\begin{array}{l}70 \\
60 \\
70 \\
60 \\
60 \\
-\overline{-} \\
40 \\
40\end{array}$ & $\begin{array}{l}656 \\
376 \\
753 \\
661 \\
230 \\
614 \\
850 \\
335 \\
420\end{array}$ & $\begin{array}{l}125 \\
158 \\
209 \\
305 \\
160 \\
\frac{-}{348} \\
390\end{array}$ & $\begin{array}{l}0.14 \\
\text { AF } \\
0.16 \\
0.14 \\
0.14 \\
\text { AF } \\
0.12 \\
0.14 \\
0.16\end{array}$ & $\begin{array}{l}0.12 \\
0.18 \\
0.16 \\
0.14 \\
0.12 \\
\frac{-}{\overline{0}} \\
0.12 \\
0.16\end{array}$ \\
\hline
\end{tabular}

AF, atrial fibrillation.

two patients (cases 6 and 7) the first heart sound was described as loud, and the $M_{1}: A_{2}$ ratios of 2.65 and 4.75 respectively confirm this.

$P R$ interval-This has a major influence on the intensity of the first heart sound. ${ }^{8}$ It was therefore measured in the patients who were in sinus rhythm. There was no significant variation between the preoperative and postoperative measurements $(\mathrm{p}=0.09, \mathrm{n}=4)$.

$Q M_{1}$ interval-In the five preoperative tracings the mean $\mathrm{QM}_{1}$ interval was $100 \mathrm{~ms}$ (range $90-120 \mathrm{~ms}$ ). After operation the mean $\mathrm{QM}_{1}$ interval fell to $64 \mathrm{~ms}$ (range $60-70 \mathrm{~ms}$ ). The preoperative and postoperative measurements were significantly different $(\mathrm{p}<0.01, \mathrm{n}=5)$. In the patients in cases 6 and 7 the $\mathrm{QM}$, time interval was 90 and $100 \mathrm{~ms}$ respectively.

Mitral valve closure rate-Using a paired $t$ test, the preoperative and postoperative mitral valve closure slope (mean $535 \mathrm{~mm} / \mathrm{s}$ ) was significantly greater than that measured postoperatively (mean $191 \mathrm{~mm} / \mathrm{s}$ ) $(\mathrm{p}<0.01, \mathrm{n}=5)($ Table 2$)$.

\section{CASES 8 AND 9}

In these two patients the preoperative measurements of $Q M_{1}$, ratio of $M_{1}: A_{2}$, and mitral valve closure rate were similar to the postoperative measurements. The preoperative ratios of $M_{1}: A_{2}$ were within the range regarded as normal. ${ }^{7}$

The notable echocardiographic feature of these two patients was the preservation of the normal diastolic pattern of motion of the mitral leaflets (Fig. 1) rather than the abnormal pattern typically seen with left atrial myxoma (Fig. 2). In the two patients with a normal $M_{1}: A_{2}$ ratio long axis parasternal views using cross sectional echocardiography showed that the tumour mass did not completely fill the mitral valve orifice in diastole.

Figure 3 shows the results of the $M_{1}: A_{2}$ ratio, the $\mathrm{QM}_{1}$ time interval, and the mitral valve closure rate in the nine patients before and after operation. 


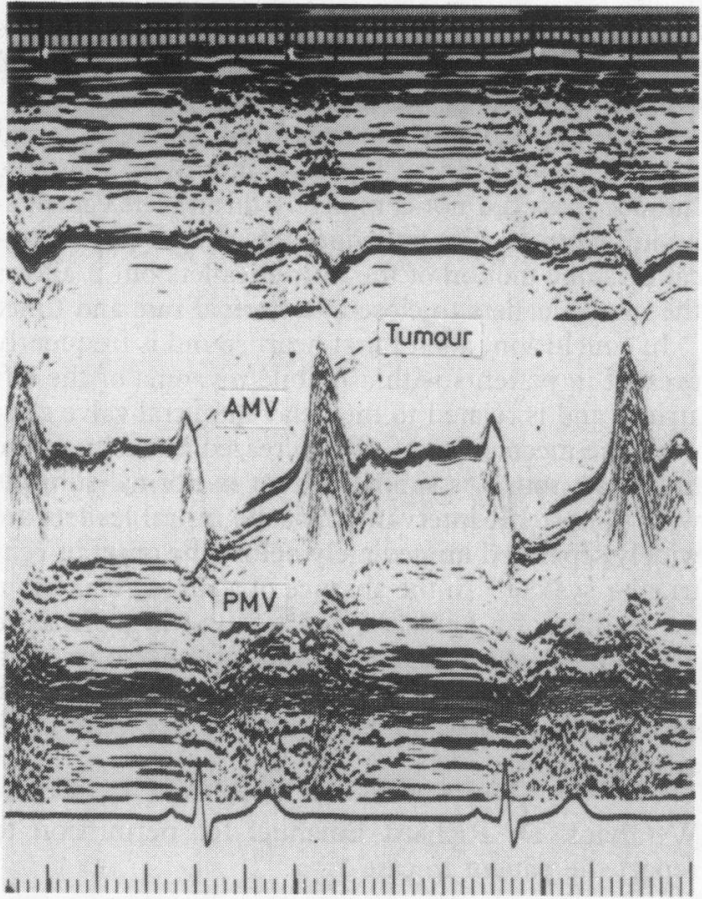

Fig. 1 Case 8: echocardiogram showing the tumour immediately behind the anterior leaflet of the mitral valve $(A M V)$. Much of the space between the anterior leaflet and the posterior leaflet $(P M V)$ is not occupied by tumour.
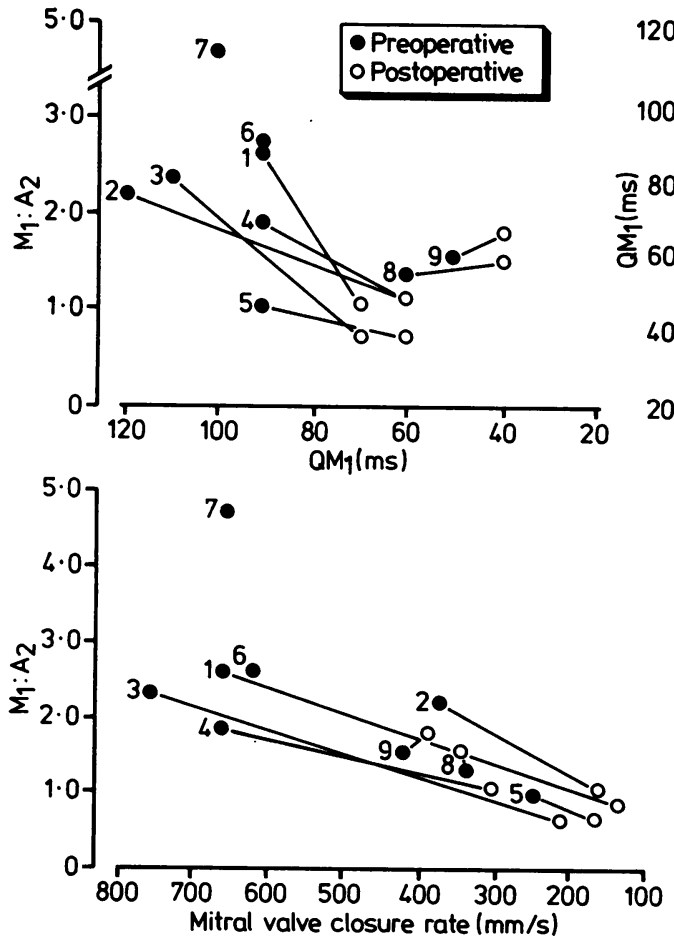

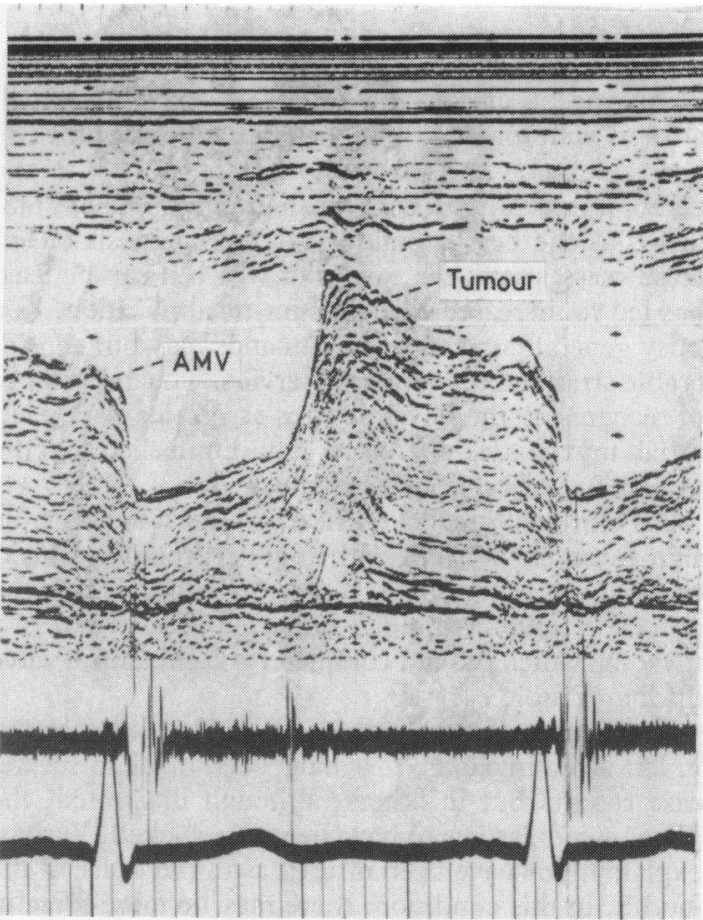

Fig. 2 Case 3: echocardiogram and phonocardiogram of left atrial myxoma. The tumour is seen throughout the cardiac cycle and completely fills the space between the anterior (AMV) and posterior mitral leaflets.

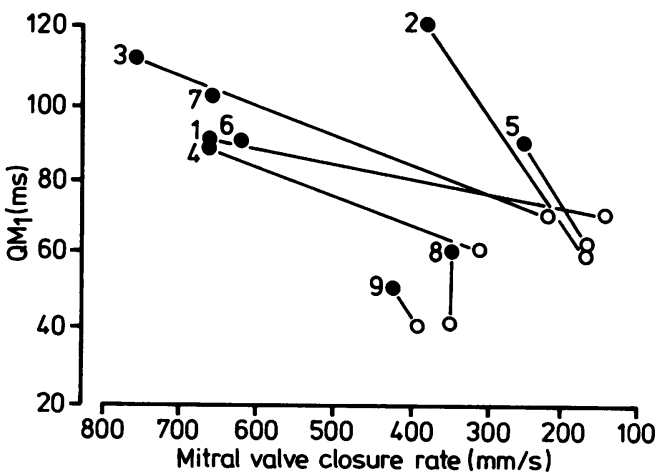

Fig. 3 Relation of $M_{1}: A_{2}$ ratio, $Q M_{1}$ interval, and mitral valve closure rate in nine patients (cases 1-9) with atrial myxoma. 


\section{Discussion}

The concept of "excluding a left atrial myxoma" attracts widespread attention, especially since the left heart is a not uncommon source of emboli to the cerebral circulation. Echocardiography is now established as the best technique for the diagnosis of left atrial masses, and the ease with which it can be used has led to increased demands for its application. In a busy general hospital these demands may put considerable strain on the available service. The importance of recognising the physical signs associated with a left atrial myxoma is therefore not diminished by the availability of echocardiography.

An extremely loud first heart sound was a notable sign in seven patients with mobile prolapsing myxomas; it was absent in two other patients in whom the echocardiographic findings indicated the presence of a myxoma which did not completely fill the mitral valve during diastole.

Comments on the loudness of the first heart sound in left atrial myxoma ${ }^{2-16}$ have been made in several case reports but in others, although illustrated, the phenomenon seems to have been overlooked. Various explantations have been offered as to the cause of the loud $S_{1}$ in this condition: there may be more forceful closure of the mitral valve ${ }^{10}$ and the loudness of $S_{1}$ may be due to tumour movement ${ }^{9-11}$ produced either through the checking of the myxoma by its stalk ${ }^{12}$ or by it striking the atrial wall and mitral valve. ${ }^{12-14}$ Furthermore a high left atrial pressure alone may be responsible. ${ }^{16}$ None of these suggestions completely explain our observations.

The long $Q M_{1}$ interval in myxoma indicates that there is delay in mitral valve closure. Mitral valve closure therefore occurs on a later and steeper part of the left ventricular pressure curve which closes the valve more rapidly than normal. This hypothesis is supported by the observations that $\mathrm{QM}_{1}$ was shorter and the rate of closure of the mitral leaflets was slower after removal of the tumour, at which time the intensity of the first heart sound had returned towards normal. The abnormally long preoperative $\mathbf{Q M}_{1}$ interval may be accounted for by the increase in left atrial pressure, which delays the left atrial-left ventricular pressure crossover, and this may be accentuated by the presence of the tumour between the mitral leaflets.

These observations on the variation of the intensity of the first heart sound are consistent with previous findings on the relation between the intensity of the first heart sound and the PR interval. ${ }^{8}$ As the PR interval lengthens, the $Q M_{1}$ interval shortens and the first heart sound becomes softer. In mitral stenosis following successful mitral valvotomy, when the left atrial pressures may be presumed to be normal, the first heart sound often remains accentuated. In this situation the abnormal fibrotic structure of the mitral cusps is responsible for the loud first heart sound.

In the two patients with a normal first heart sound the $M$ mode echocardiograms indicated that the tumour mass did not completely fill the left ventricular inflow tract. Not only does this permit physiological diastolic motion of the mitral leaflets but it allows the mitral leaflets to close at a normal rate and time.

In conclusion, a loud first heart sound is frequently present in patients with a mobile myxoma of the left atrium and is related to the delay in mitral valve closure. The mechanism of this increased intensity of the first heart sound is similar to that in normal subjects with a short PR interval, when the mitral leaflets are widely separated immediately before the onset of ventricular systole. ${ }^{8}$ In the absence of a short PR interval the finding of a loud first heart sound in patients in whom there is a clincal suspicion of a myxoma is an indication for echocardiography. The absence of this sign, however, does not exclude the presence of a left atrial tumour.

We thank Dr Richard Emanuel for permission to report the patient in case 1 .

\section{References}

1 Donaldson RM, Emanuel RW, Earl CJ. The role of two-dimensional echocardiography in the detection of potentially embolic intra-cardiac masses in patients with cerebral ischaemia. I Neurol Neurosurg Psychiatry 1981; 44: 803-9.

2 Goodwin JF, Stanfield CA, Steiner RE, et al. Clinical features of left atrial myxoma. Thorax 1962; 17: 91-110.

3 Likoff W, Geckeler GD, Gregory JE. Functional mitral stenosis produced by an intra-atrial tumor. Am Heart $\mathcal{F}$ 1954; 47: 619-25.

4 Jones GP, Julian DG. Left atrial tumour simulating mitral stenosis. Br Med f 1955; ii: 361-2.

5 Goodwin JF. Diagnosis of left atrial myxoma. Lancet 1963; i: 464-8.

6 Leatham A. Auscultation of the heart and phonocardiography. 2nd ed. Edinburgh: Churchill Livingstone, 1975.

7 Brooks $\mathrm{N}$. The intensity and splitting of the first heart sound. London, 1978. MD Thesis.

8 Leech G, Brooks N, Green-Wilkinson A, Leatham A. Mechanism of influence of $P R$ interval on loudness of first heart sound. Br Heart $f$ 1980; 43: 138-42.

9 Greenwood WF. Profile of atrial myxoma. Am $\mathcal{F}$ Cardiol 1968; 21: 367-75.

10 Ghahramani A, Arnold JR, Hildner FJ, Sommer LS, Samet P. Left atrial myxoma: hemodynamic and phonocardiographic features. Am $\mathcal{F}$ Med 1972; 52: 52532.

11 Zitnik RS, Giuliana ER. Clinical recognition of atrial 
myxoma. Am Heart f 1970; 80: 689-700.

12 Abbott OA, Warshawski FE, Cobbs BW Jr. Primary tumors and pseudo-tumors of the heart. Ann Surg 1962; 155: 855-72.

13 Penny JL, Gregory JJ, Ayres SM, Giannelli S Jr, Rossi P. Calcified left atrial myxoma simulating mitral insufficiency. Hemodynamic and phonocardiographic effects of tumor movement. Circulation 1967; 36: 417-21.

14 Pitt A, Pitt B, Schaefer J, Criley JM. Myxoma of the left atrium. Hemodynamic and phonocardiographic consequences of sudden tumor movement. Circulation 1967; 36: 408-16.

15 Craige E, Algary WP. Left atrial myxoma. Diagnosis with the help of the phonocardiogram and apexcardiogram. Arch Intern Med 1972; 129: 470-4.

16 Wassermil M, Warkentin DL, Ravin A. Myxoma of the left atrium. Phonocardiographic study of 3 cases. Circulation 1961; 25: 50-6. 